(с) М.В. Шестакова*, Н.Г. Мокрышева, И.И. Дедов

Национальный медицинский исследовательский центр эндокринологии, Москва

В 2020 г. мир столкнулся с беспрецедентным вызовом для здоровья людей, связанным со вторжением нового коронавируса SARS COV-2. Это также вызов и для систем здравоохранения всех стран мира. Наиболее уязвимыми в данных условиях оказались пациенты с сахарным диабетом (СД) вследствие особенностей состояния их иммунного статуса и иммунного ответа на вирусную атаку, вследствие чрезмерно высокой активности вируса в условиях гипергликемии, вследствие коморбидности и ожирения, которые часто сопутствуют течению СД. Тяжелое течение заболевания COVID-19 требует обязательного пересмотра привычной сахароснижающей терапии. Крайне важным остается сохранение оптимального контроля гликемии, предупреждение развития кетоацидоза, в связи с чем в большинстве случаев приоритетным препаратом для контроля гликемии становится инсулин. Продолжаются поиски новых препаратов для борьбы с коронавирусной инфекцией, стартуют новые рандомизированные клинические испытания препаратов. В качестве кандидатов на потенциально эффективные средства для борьбы с коронавирусом испытываются в том числе и инновационные антидиабетические средства.

КЛЮЧЕВЫЕ СЛОВА: коронавирус; COVID-19; сахарный диабет; ангиотензинпревращающий фермент типа 2; глюкокортикоиды

\title{
COURSE AND TREATMENT OF DIABETES MELLITUS IN THE CONTEXT OF COVID-19
}

\author{
(c) Marina V. Shestakova*, Natalia G. Mokrysheva, Ivan I. Dedov
}

Endocrinology Research Centre, Moscow, Russia

In 2020, the world is facing a historically unparalleled public health challenge associated with the invasion of the new severe acute respiratory syndrome coronavirus-2 (SARS-CoV-2). This is also a challenge for the healthcare systems worldwide. Patients with diabetes mellitus (DM) are most vulnerable to COVID-19 because of the peculiarities of their immune response to a virus attack and due to their high susceptibility to viral activity because of hyperglycemia and other comorbid conditions and obesity that often accompany DM. The severity of the COVID-19 disease requires a mandatory review of the usual anti-hyperglycemic therapy. Maintaining optimal glycemic control and preventing the development of ketoacidosis remain extremely important; therefore, insulin becomes the priority drug for glycemic control in most cases. The search for new drugs to fight against the coronavirus infection continues with new randomised clinical drug trials being launched. Innovative anti-diabetic agents are also being tested as candidates for potentially effective anti-coronavirus agents.

KEYWORDS: coronavirus; COVID-19; diabetes mellitus; type 2 angiotensin-converting enzyme; glucocorticoids

Прошло немногим более 150 дней, как новый коронавирус SARS COV-2 начал свою атаку на нашу планету и дал начало новой болезни, получившей название COVID-19. При осложненном течении болезнь приводит к развитию острого респираторного дистресс-синдрома вследствие вирусной пневмонии и к гибели больных от дыхательной недостаточности. Эпидемия, начавшаяся в китайской провинции Ухань в декабре 2019 г., беспрецедентно быстро распространилась по всем без исключения странам и континентам. По данным Всемирной организации здравоохранения (ВО3), на 28.05.2020 г. насчитывается более 5,7 млн заболевших (с лабораторно подтвержденным диагнозом) и более 356 тыс. умерших людей от последствий вирусной пневмонии. Каждый день эта цифра прирастает не менее чем на 70 тыс. новых подтвержденных случаев коронавирусной инфекции [1]. В России на эту же дату (28.05.2020 г.) зарегистрировано 379 тыс. заболевших и более 4 тыс. умерших людей [1].

В связи со сложившейся неблагоприятной эпидемиологической ситуацией жизнь людей во всем мире поделилась на «ДО» и «ПОСЛЕ» вирусного вторжения! Во избежание передачи вируса воздушно-капельным и контактным путями повсеместно введены режимы карантина или самоизоляции, обязательное ношение средств индивидуальной защиты (масок, перчаток), закрыты рестораны, кафе, клубы, театры, кинотеатры, парки и другие места общего сбора людей, прекращены плановые авиа- и железнодорожные сообщения между странами. В настоящее время такие меры - это единственное эффективное средство профилактики распространения вирусной инфекции. 


\section{ЧАСТОТА РАЗВИТИЯ COVID-19 И ТЯЖЕСТЬ ЗАБОЛЕВАНИЯ У БОЛЬНЫХ САХАРНЫМ ДИАБЕТОМ}

Наиболее уязвимыми категориями людей, подверженных данному заболеванию, являются пациенты с тяжелыми хроническими заболеваниями, такими как болезни сердца и сосудов (ишемическая болезнь сердца (ИБС), сердечная недостаточность, артериальная гипертензия, цереброваскулярные заболевания), хроническая обструктивная болезнь легких (ХОБЛ), хроническая болезнь почек и, конечно же, сахарный диабет (СД). Анализ, проведенный различными группами ученых из Китая, Италии и США, показал неодинаковую встречаемость подтвержденного инфицирования SARS COV-2 у больных СД. Так, по данным центров профилактики и контроля заболеваний, частота СД среди заболевших COVID-19 составила 5,3\% из 20892 больных в Китае [2], 10,9\% из 7162 больных в США [3] и 35,5\% из 355 больных в Италии [4]. В России эти данные, поступающие в Федеральный регистр COVID-19, еще предстоит проанализировать. Сбор информации о больных СД в период эпидемии идет в том числе посредством регистрации случаев перенесенной инфекции и ее исходов в базе данных «Российского регистра больных СД» (diaregistry.ru).

Если сравнивать данные о распространенности COVID-19 в Китае и США (5,3\% и 10,9\% соответственно) с общей распространенностью СД в этих странах (10,9\% и 13,3\% соответственно) [5], то становится очевидно, что число инфицированных больных СД не превышает общую распространенность диабета в этих странах. Это означает, что риски заболеть этой болезнью у больных СД не превышают таковые риски в общей популяции. Однако если человек с СД уже инфицирован новым коронавирусом SARS COV-2, то болезнь у него течет гораздо тяжелее, чем у пациентов, не имеющих СД, и частота смертельных исходов у пациентов с СД значимо выше. Этот факт подтвержден в ряде исследований китайских коллег, опыт которых суммирован в обзоре [6]. Согласно приведенным в обзоре исследованиям, частота тяжелого течения COVID-19 была в 1,3-3,9 раз выше, а частота летальных исходов в 1,5-4,4 раза выше у людей с СД по сравнению с людьми без СД [6]). Только что опубликованный метаанализ 30 исследований, описывающий исходы пневмонии COVID-19, подтверждает, что у больных СД отмечаются значимо более высокие риски тяжелого течения заболевания ( $R R=2,45 ; 95 \%$ ДИ 1,79-3,35; $p<0,001)$, более частое развитие острого респираторного дистресс-синдрома $(\mathrm{RR}=4,64$; 95\% ДИ 1,86-11,58; $\mathrm{p}=0,001)$ и более высокая смертность (RR=2,12; 95\% ДИ 1,44-3,11; $<<0,001)$, чем у лиц без СД [7].

\section{ПОЧЕМУ БОЛЬНЫЕ СД ПОДВЕРЖЕНЫ БОЛЕЕ ТЯЖЕЛОМУ ТЕЧЕНИЮ COVID-19?}

Склонность больных СД к более тяжелому течению болезни с большей частотой летальных исходов может быть объяснена особенностями взаимодействия вируса и его рецептора в условиях гипергликемии, особенностями иммунного ответа и состоянием здоровья больных СД в целом.

Экспрессия AПФ2 (рецептора вируса SARS COV-2) при СД Вирус SARS COV-2 для того, чтобы внедриться в клетки-мишени человека (прежде всего в альвеолярные клетки легких), должен вступить в контакт со своим рецептором. Установлено, что таким рецептором для нового коронавируса является ангиотензинпревращающий фермент типа 2 (АПФ2) [8]. Экспрессия этого фермента достаточно высока на слизистой полости рта, носоглотки и в ткани легких (в альвеолярных клетках типа 2) [9, 10]. Именно поэтому «входными воротами» для вируса являются верхние дыхательные пути, после чего вирус легко проникает в легкие и поражает альвеолы, вызывая быстрое развитие пневмонии и дыхательной недостаточности. Экспрессия АПФ2 также высока в клетках энтероцитов толстой кишки, клетках миокарда, проксимальных почечных канальцах, печени, поджелудочной железы (рис. 1) [11]. Такая локализация экспрессии рецептора к новому коронавирусу может объяснять и другие проявления заболевания, такие

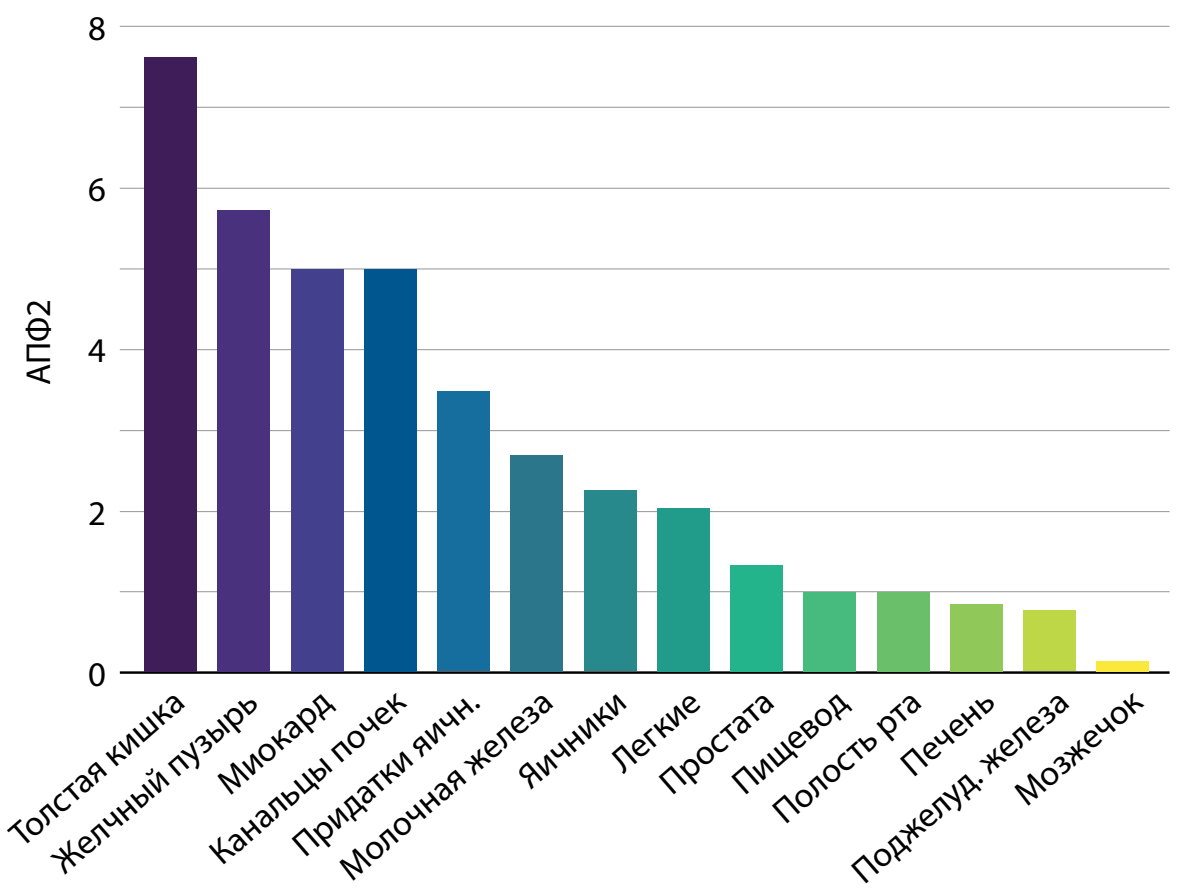

Рис. 1. Локализация экспрессии ангиотензинпревращающего фермента типа 2 в тканях человека (адаптировано [9]): АПФ2 - Ангиотензинпревращающий фермент 2. 
как диарея, потеря обоняния, впервые возникшая транзиторная гипергликемия.

После того, как спайк вируса соединился со своим АПФ2-рецептором на поверхности клеток-мишеней, трансмембранная сериновая протеаза (TMPRSS2) «разрезает» АПФ2-рецептор, что приводит к активации спайка вируса, и он вместе с рецептором внедряется в клетку, где и происходит дальнейшая его репликация [11]. В экспериментальных исследованиях на мышах было показано, что в условиях гипергликемии в ряде органов и тканей (почки, печень, поджелудочная железа) экспрессия АПФ2 повышается многократно [12]. При этом доказано, что при наличии гипергликемии в ткани легких активируется процесс гликозилирования рецептора АПФ2 (т.е. связывание белка с глюкозой), что повышает его аффинность к вирусу SARS COV-2 [13]. Следовательно, при СД повышаются не только экспрессия рецептора (во многих тканях), но и его связываемость с коронавирусом. Оба процесса приводят к большей чувствительности больных СД к вирусной атаке.

\section{Гипергликемия как «провокатор» цитокинового}

\section{«шторма»}

После внедрения вируса в организм человека происходят его распознавание иммунокомпетентными клетками и индукция так называемого «цитокинового шторма» с выбросом большого количества провоспалительных цитокинов (TNF, IL-1 $\beta$, IL-6, IL-8, IL-17 и др.) и хемокинов (MCP1, IP10, MIP1a) [14]. Недавние публикации свидетельствуют о том, что в условиях инфицирования вирусом гриппа у больных СД активность маркеров воспалительных реакций (С-реактивный белок, уровень ферритина, фибриногена, IL-6, D-димера) значимо выше, чем у пациентов без СД [15]. Иными словами, при СД выброс цитокинов в ответ на вирусную инфекцию происходит гораздо интенсивнее, чем при нормальном углеводном обмене. Почему так происходит? Ответ был получен в недавнем исследовании, где было показано, что реализация иммунного ответа и активность воспалительных реакций напрямую зависят от обеспеченности этих процессов энергией и количеством поглощенной глюкозы иммунными клетками. Повышенная экспрессия IL-6 и IL-8 у пациентов с вирусной инфекцией показала прямую зависимость от высокого уровня гликемии [16]. Глюкоза является как бы источником энергии, «топливом» для бурных иммунологических реакций! Следовательно, пациенты с СД с неудовлетворительным контролем гликемии подвержены более высокой активности «цитокинового шторма» и риску неблагоприятного исхода вирусной инфекции.

Эта гипотеза подтверждается данными наблюдения китайских врачей, обобщивших опыт лечения атипичной пневмонии у больных СД, вызванной коронавирусом первого поколения - SARS COV - в 2002 г. Они показали, что риск летальности был в 3 раза выше у больных СД суровнемглюкозыплазмы натощак (ГПН) более 8 ммоль/л по сравнению с пациентами с ГПН менее 6 ммоль/л [17]. Эпидемия нового коронавируса SARS COV-2 демонстрирует те же закономерности. Смертность людей с гликемией 10 ммоль/л (180 мг/дл) в 3 раза выше, чем лиц с гликемией 6,4 ммоль/л (116 мг/дл): 28,8\% и 6\% соответственно [18]).
Коморбидность при СД 2 типа как причина более тяжелого течения COVID-19

СД 2 типа (СД 2) - это тяжелое хроническое заболевание, которое часто сочетается с патологией сердечно-сосудистой системы (артериальная гипертония, ИБС, сердечная недостаточность, цереброваскулярные заболевания, хроническая болезнь почек), которые развиваются либо как проявление сосудистых осложнений диабета, либо как сопутствующие конкурирующие заболевания. В недавно опубликованном метаанализе Wang и соавт. [19], включавшем 1558 больных с COVID-19, было показано, что эти сопутствующие заболевания существенно повышают риски тяжелого течения вирусного заболевания: наличие артериальной гипертензии повышало эти риски в 2,29 раза $(\mathrm{P}<0,001)$, ХОБЛ - в 5,97 раза $(\mathrm{P}<0,001)$, сердечно-сосудистой патологии - в 2,93 раза $(\mathrm{P}<0,001)$, цереброваскулярной болезни - в 3,89 раза $(\mathrm{P}=0,002)$. Однако не было найдено такой взаимосвязи с болезнями печени, онкологическими заболеваниями и патологией почек. Таким образом, больные СД в сочетании с перечисленными заболеваниями имеют значимо бо́льшие риски тяжелого течения новой коронавирусной инфекции.

\section{Ожирение как самостоятельный фактор риска}

тяжелого течения COVID-19

Установлено, что более 80\% больных СД2 страдают избыточным весом и ожирением [20]). По данным недавних публикаций американских и французских исследователей, ожирение оказалось самостоятельным фактором риска тяжелого течения COVID-19. Так, в отчете сети эпиднадзора США (COVID-NET), опубликованном 17 апреля 2020 г. и включающем данные о госпитализации пациентов с 1 по 30 марта в 14 штатах США, почти половина из них $(48,3 \%)$ имели ожирение [21]. Это несколько выше, чем распространенность ожирения в США, составляющая 42,4\% по данным на 2018 г. [22]. Аналогичная ситуация отмечена во Франции, где люди с ожирением составляли 47,6\% от всех госпитализированных с диагнозом COVID-19, что в 2 раза превышает показатели официальной распространенности ожирения во Франции - 21,6\%. Из них 14,5\% имели морбидное ожирение

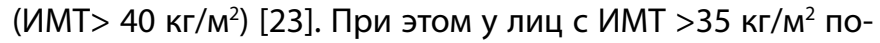
требность в переводе пациентов на искусственную вентиляцию легких возрастала в 1,6 раза независимо от возраста, наличия артериальной гипертензии и СД. Таким образом, наличие ожирения у больных СД2 является дополнительным независимым фактором риска тяжелого течения COVID-19.

\section{КАКАЯ КОРРЕКЦИЯ САХАРОСНИЖАЮЩЕЙ ТЕРАПИИ СД ТРЕБУЕТСЯ В УСЛОВИЯХ COVID-19?}

Этот вопрос в настоящее время остается открытым, поскольку в столь сжатые сроки (150 дней от начала всемирной эпидемии) убедительных доказательств о пользе или вреде тех или иных групп антигипергликемических препаратов не получено. Основными ориентирами к назначению или отмене препаратов служат инструкции к применению препаратов, информация об их побочных действиях, а также рекомендации по лечению гипергликемии в условиях тяжелых инфекционных заболеваний и в отделениях интенсивной терапии. 


\begin{tabular}{|c|c|}
\hline $\begin{array}{l}\text { Легкое } \\
\text { течение }\end{array}$ & $\begin{array}{l}\text { - } \quad \text { T<38 C, кашель, слабость, боли в горле } \\
\text { - } \quad \text { Отсутствие критериев среднетяжелого и тяжелого течения }\end{array}$ \\
\hline $\begin{array}{c}\text { Среднетяжелое } \\
\text { течение }\end{array}$ & $\begin{array}{ll}\cdot & \mathrm{T}>38^{\circ} \mathrm{C} \\
\cdot & \text { чДД>22 } \\
\text { - } & \text { Одышка при физических нагрузках } \\
\text { - } & \text { Пневмония (подтвержденная с помощью КТ легких) } \\
\text { - } & \text { SpО }<95 \% \\
\text { - } & \text { РБ сыворотки крови > } 10 \text { мг/л }\end{array}$ \\
\hline $\begin{array}{l}\text { Тяжелое } \\
\text { течение }\end{array}$ & $\begin{array}{ll}\text { - } & \text { чДД более } 30 \\
\text { - } & \mathrm{SpO}_{2} \leq 93 \% \\
\text { - } & \text { Прогресс } / \mathrm{FiO}_{2} \leq 300 \text { мм рт.ст. } \\
& \text { рентгеногравание изменений в легких по данным } \\
& \text { более чем на } 50 \% \text { через 24-48 ч) } \\
\text { - } & \text { Снижение уровня сознания, ажитация } \\
\text { - } & \text { Нестабильная гемодинамика (систолическое АД <90 мм рт.ст. } \\
& \text { или диастолическое АД <60 мм рт.ст., диурез <20 мл/ч) } \\
\text { - } & \text { Лактат артериальной крови >2 ммоль/л } \\
\text { - } & \text { qSOFA > } 2 \text { балла }\end{array}$ \\
\hline $\begin{array}{c}\text { Крайне тяжелое } \\
\text { течение }\end{array}$ & $\begin{array}{l}\text { - } \quad \text { ОДН с необходимостью респираторной поддержки (ИВЛ) } \\
\text { - } \quad \text { Септический шок } \\
\text { - } \quad \text { Полиорганная недостаточность }\end{array}$ \\
\hline
\end{tabular}

Рис. 2. Классификация COVID-19 по степени тяжести [24].

чДД - частота дыхательных движений; КТ - компьютерная томография; ОДН - острая дыхательная недостаточность; СРБ - С-реактивный белок; ИВЛ-искусственная вентиляция легких; $\mathrm{SpO}_{2}$ - насыщение крови кислородом; $\mathrm{PaO}_{2}$ - парциальное давление кислорода; FiO 2 - фракция вдыхаемого кислорода; qSOFA - quick Sequential Organ Failure Assessment, шкала быстрой последовательной оценки органной недостаточности.

Решение вопроса об изменении сахароснижающей терапии у больного СД, заболевшего COVID-19, принимается на основании тяжести течения COVID-19 и качества контроля гликемии.

\section{Тяжесть течения COVID-19.}

Согласно «Временным методическим рекомендациям: профилактика, диагностика и лечение новой коронавирусной инфекции (COVID-19)» М3 РФ, 6-я версия от 28.04.20 [24], выделяют 4 степени тяжести течения данного заболевания (рис. 2).

\section{Целевые значения гликемии}

Основными индикаторами контроля гликемии в условиях острой вирусной инфекции являются в большей степени показатели ежедневного самоконтроля гликемии или систем суточного мониторирования гликемии (CGM, Flash-мониторинг), нежели уровень $\mathrm{HbA}_{1 c}$.

При легком и бессимптомном течении заболевания COVID-19 требования к контролю гликемии остаются прежними (как в доинфекционном периоде). Максимальные значения гликемии в течение суток не должны превышать 8 ммоль/л, при суточном мониторировании гликемии системами CGM время в диапазоне от 4 до 8 ммоль/л должно быть не менее 70\% для молодых людей и не менее $50 \%$ для пожилых и ослабленных [25].

При среднетяжелом и тяжелом течении ориентирами служат рекомендации для больных диабетом в период острых заболеваний [26]. С целью профилактики развития как кетоацидоза, так и гипогликемических состояний важно поддерживать уровни гликемии перед едой 6-7 ммоль/л, в течение дня - до 10 ммоль/л.

\section{Пациенты с СД 1 типа}

Продолжают терапию инсулином в прежних дозах. Более часто мониторируют гликемию (не реже 7-8 раз в сутки). При повышении ГПН более 13-15 ммоль/л измеряют уровень кетонов в моче, увеличивают дозы инсулина короткого (ИКД) и ультракороткого действия (ИУКД) во время плановых инъекций перед едой. Не рекомендуется делать инъекции чаще чем 1 раз в 3-4 ч (для ИКД) или 2-3 ч (для ИУКД), следует сначала оценить действие предыдущей дозы.

Идеальным решением для удержания гликемического контроля в целевых значениях могло бы быть применение инсулиновых помп с функциями обратной связи (или с функцией остановки подачи инсулина при развитии гипогликемии), что позволило бы достигать оптимальных параметров гликемии без рисков гипогликемических состояний.

\section{Пациенты с СД 2 типа}

При нетяжелом течении заболевания (температура <38,5 ${ }^{\circ} \mathrm{C}$, отсутствие одышки, достаточная сатурация крови кислородом $\mathrm{SpO}_{2}>93 \%$ ) и ГПН <13 ммоль/л, отсутствии кетонурии.

Больные СД2 продолжают текущую терапию (любые классы препаратов). Метформин остается базовым препаратом при его переносимости. Опубликовано несколько масштабных исследований, свидетельствующих о том, что лечение метформином больных с хроническими респираторными заболеваниями [27] и даже с обструктивной болезнью легких [28] в течение нескольких лет приводило к значимому снижению риска смертности по сравнению с больными, не получавшими этот препарат. 
При среднетяжелом и тяжелом течении заболевания (лихорадка, одышка, пневмония, снижение сатурации крови кислородом $\left.\mathrm{SpO}_{2}<93 \%\right)$ и ГПН <13 ммоль/л, отсутствии кетонурии.

Как отечественные (ФГБУ «НМИЦ эндокринологии» МЗ РФ) [29, 30], так и международные эксперты [25, 31, 32] рекомендуют отмену метформина, препаратов сульфонилмочевины (с высоким риском гипогликемии), агонистов рецепторов глюкагоноподобного пептида 1 (ГПП-1) и глифлозинов. При среднетяжелом течении условно можно продолжить терапию ингибиторами дипептидилпептидазы 4 (ДПП4), препаратами сульфонилмочевины с низким риском гипогликемии (гликлазид МВ). При отмене вышеуказанных препаратов к терапии добавляется инсулин в дозах, позволяющих удерживать целевые значения гликемии.

\section{КАКИЕ ОПАСЕНИЯ ВОЗНИКАЮТ В СВЯЗИ С ПРИМЕНЕНИЕМ РЯДА САХАРОСНИЖАЮЩИХ ПРЕПАРАТОВ?}

Метформин. В условиях гипертермии, дегидратации и гипоксии, вызванной поражением альвеол, применение метформина повышает риски развития лактатацидоза, что требует его отмены. Важно помнить, что метформин противопоказан при снижении скорости клубочковой фильтрации (СКФ) <30 мл/мин/1,73м², при развитии острой почечной недостаточности, при септическом шоке и других состояниях, сопровождающихся выраженной гипоксией. Однако имеются данные, полученные на большой когорте пациентов с СД2 $(\mathrm{n}=7404)$, находившихся в отделениях интенсивной терапии Дании по разным причинам, в том числе с тяжелой пневмонией, что применение этого препарата за 90 дней до развития критически тяжелого состояния снижало летальность на 17-20\% по сравнению с больными, не получавшими метформин [33].

Препараты сульфонилмочевины (ПСМ). При гипертермии дозы этих препаратов следует увеличивать до максимальных. Однако нужно помнить, что применение ПСМ сопряжено с высоким риском развития гипогликемических состояний (особенно прием глибенкламида). Гипогликемии являются одним из наиболее опасных факторов риска развития тяжелых сердечно-сосудистых исходов. Поэтому у всех лиц с высоким риском гипогликемии (пожилые, больные с нарушенной функцией почек, сердечно-сосудистыми заболеваниями) применение ПСМ не рекомендуется, за исключением препаратов с низким риском гипогликемии (например, гликлазид МВ).

Агонисты рецепторов ГПП-1. Частыми побочными эффектами этих препаратов являются тошнота, рвота, потеря аппетита. Эти симптомы могут усугубить имеющуюся дегидратацию у больных с тяжелой формой COVID-19. Кроме того, эти же симптомы могут «замаскировать» развивающийся кетоацидоз, что приведет к позднему назначению инсулина и тяжелой декомпенсации заболевания. Поэтому при появлении диспепсических симптомов агонисты рецепторов ГПП-1 следует отменить. При хорошей переносимости препаратов они могут быть продолжены.

Ингибиторы натрийглюкозного транспортера 2 (НГЛТ2) (глифлозины). В условиях гипертермии и дегидратации эти препараты могут спровоцировать раз- витие эугликемического кетоацидоза, поэтому их рекомендовано отменять. Однако американские ученые предположили, что, возможно, эта группа препаратов может оказать защитный эффект у больных COVID-19, замедлить прогрессирование заболевания и снизить частоту летальных исходов. Американский Институт сердца Святого Луки и компания «Астра Зенека» инициировали беспрецедентно смелое рандомизированное двойное слепое плацебо-контролируемое клиническое исследование 3-й фазы (DARE-19) по применению ингибитора НГЛт2 дапаглифлозина в качестве препарата для предупреждения тяжелых исходов COVID-19 не только у больных СД2, но и у пациентов с ИБС, сердечной недостаточностью или патологией почек даже в отсутствие СД2 [34]. Поводом для такого решения послужили данные масштабного исследования DECLARE [35], продемонстрировавшие защитное действие дапаглифлозина на сердце и почки у пациентов с СД2, а также исследование DAPA-HF [36], показавшее снижение прогрессирования сердечной недостаточности у лиц в том числе без СД2. В исследовании примут участие больные с легкой и среднетяжелой стадиями COVID-19. Длительность терапии дапаглифлозином в дозе 10 мг составит 30 дней. В качестве исходов будет оценено время до наступления смерти либо до развития функциональной недостаточности органов и систем [34].

Ингибиторы ДПП4. Препараты в целом имеют хорошую переносимость. Предположительно их прием можно продолжить при среднетяжелом течении заболевания. Исключение составляет препарат саксаглиптин, который в исследовании SAVOR-TIMI 53 приводил к более частой госпитализации больных в связи с сердечной недостаточностью. Также необходимо помнить, что в редких случаях препараты могут вызвать симптомы острого панкреатита. В этом случае они немедленно отменяются.

Тиазолидиндионы (глитазоны). Не рекомендуются вследствие опасности задержки жидкости, развития отечного синдрома и прогрессирования сердечной недостаточности.

При любой степени тяжести заболевания и ГПН > 13-15 ммоль/л. Рекомендовано начало инсулинотерапии. Схемы перевода пациентов с СД2 на инсулинотерапию подробно изложены в «Алгоритмах специализированной медицинской помощи больным сахарным диабетом, 9-й выпуск» [37].

\section{ДИСКУССИОННЫЕ ВОПРОСЫ ЛЕЧЕНИЯ БОЛЬНЫХ СД в УслОвияХ COVID-19}

\section{Вопрос применения глюкокортикоидов (ГК)}

Синтетические ГК уже давно применяются для лечения аутоиммунных заболеваний в связи с их выраженной иммуносупрессивной активностью. ГК являются мощными регуляторами воспаления. В воспаленной ткани они взаимодействуют с макрофагами и подавляют синтез эйкозаноидов, которые являются медиаторами, вызывающими расширение сосудов и повышение их проницаемости. ГК ингибируют экспрессию многих провоспалительных цитокинов, включая интерлейкины (IL) IL-1a, IL-1 $\beta$, IL-2, IL-3, IL-4, IL-5, IL-6, IL-11, IL-12, IL-13, IL-16, IL-17, интерферон-ү (IFNץ), фактор некроза опухолей (TNF), а также ослабляют передачу сигнала от цитокинового рецептора. ГК иници- 
ируют программы генов в моноцитах и макрофагах, которые способствуют фагоцитозу «умерших» клеток и остального клеточного мусора. Все эти эффекты ГК подробно освещены в обзоре Petrillo и соавт. [38].

Учитывая столь мощный противовоспалительный потенциал ГК, эти препараты широко начали применяться в лечении COVID-19 с целью подавления «цитокинового шторма». Однако в процессе назначения этих препаратов возникли опасения в связи с более частым развитием осложнений заболевания, включая острый респираторный дистресс-синдром, или усилением репликации вируса, выявленной по более высокой концентрации вирусной РНК через 2-3 нед после начала лечения ГК (по сравнению с группой плацебо) [39]. Детальный анализ этих исследований позволяет предположить, что наиболее важным для получения позитивного противовоспалительного эффекта ГK в лечении COVID-19 является время назначения препаратов и их дозы. Высокие «пульсовые» 1-2 дозы препаратов в острой фазе инфекции могут очень эффективно подавить воспалительную реакцию, в то время как длительное введение ГК может провоцировать интенсивную репликацию вируса. Эта гипотеза подтверждается исследованиями, где высокие дозы стероидов оказывали благоприятный эффект на течение острого респираторного дистресс-синдрома, но не в условиях коронавируса [40].

\section{Вопрос применения блокаторов ренин-}

ангиотензиновой системы (РАC)

Вопрос о применении блокаторов РАС горячо обсуждается в отечественной и мировой литературе в связи с приходом пандемии COVID-19. Такие препараты, как ингибиторы АПФ (иАПФ) и блокаторы рецепторов ангиотензина II (БРА), являются наиболее эффективными и назначаемыми при артериальной гипертензии, диабетической нефропатии, сердечной недостаточности. При этом хорошо известно, что эти группы препаратов значимо повышают экспрессию фермента АПФ2, который одновременно является рецептором нового коронавируса SARS COV-2 [8]. Поэтому, чисто теоретически, возникло опасение, что эти препараты могут спровоци- ровать более интенсивное связывание вируса со своими рецепторами - АПФ2, которых стало больше на блокаторах РАС, и более активное проникновение вируса в клетки. Однако за прошедшие 150 дней от начала коронавирусной атаки не поступило ни одного убедительного доказательства об ухудшении течения COIVID-19 у людей, получающих блокаторы РАС. В ретроспективном анализе 112 китайских инфицированных больных не было достоверных различий в приеме блокаторов РАС между выжившими и умершими [41].

Ведущие международные и российские медицинские ассоциации сделали единодушные заявления, что в связи с отсутствием каких-либо доказательств о вреде иАПФ или БРА в контексте пандемии COVID-19 сохраняются настоятельные рекомендации продолжить терапию препаратами, блокирующими РАC $[42,43]$.

Представленные в обзоре данные в основном базируются на результатах наблюдений китайских, американских и итальянских врачей-исследователей, поскольку в этих странах в сложившейся ситуации накопился наибольший опыт борьбы с коронавирусной инфекцией. В России вся информация об инфицированных больных стекается в единый Федеральный регистр COVID-19. В свою очередь, ФГБУ «НМИЦ эндокринологии» МЗ РФ инициировало сбор информации о больных СД (1 и 2 типов), перенесших пневмонию с февраля 2020 г. (в рамках Регистра больных сахарным диабетом). Анализ полученных в Регистре сахарного диабета данных будет представлен в ближайших выпусках журнала «Сахарный диабет».

\section{ДОПОЛНИТЕЛЬНАЯ ИНФОРМАЦИЯ}

Конфликт интересов. Авторы декларируют отсутствие явных и потенциальных конфликтов интересов, связанных с публикацией настоящей рукописи.

Участие авторов. Шестакова М.В. - написание, редактирование и финальное утверждение рукописи; Мокрышева Н.Г. - редактирование и финальное утверждение рукописи; Дедов И.И. - редактирование и финальное утверждение рукописи. Все авторы внесли значимый вклад в проведение исследования и подготовку статьи, прочли и одобрили финальную версию статьи перед публикацией.

\section{СПИСОК ЛИТЕРАТУРЫ | REFERENCES}

1. World Health Organization. Coronavirus disease (COVID-2019) situation reports. Avalable from: https://www.who.int/emergencies/ diseases/novel-coronavirus-2019/situation-reports

2. Epidemiology Working Group for Ncip Epidemic Response. [The epidemiological characteristics of an outbreak of 2019 novel coronavirus diseases (COVID-19) in China. (In Chinese)]. Zhonghua Liu Xing Bing Xue Za Zhi. 2020;41 (2):145-151. doi: https://doi.org/10.3760/cma.jissn.0254-6450.2020.02.003

3. CDC. Preliminary estimates of the prevalence of selected underlying health conditions among patients with coronavirus disease 2019 - United States, February 12 - March 28, 2020. MMWR. 2020;69(13):382-386.

4. Onder G, Rezza G, Brusaferro S. Case-fatality rate and characteristics of patients dying in relation to COVID-19 in Italy. JAMA. 2020. doi: https://doi.org/10.1001/jama.2020.4683

5. International Diabetes Federation. IDF Diabetes Atlas, 9th dn. Brussels, Belgium; 2019.

6. Singh AK, Gupta R, Ghosh A, Misra A. Diabetes in COVID-19: Prevalence, pathophysiology, prognosis and practical considerations. Diabetes Metab Syndr. 2020;14(4):303-310. doi: https://doi.org/10.1016/j.dsx.2020.04.004
7. Huang I, Lim MA, Pranata R. Diabetes mellitus is associated with increased mortality and severity of disease in COVID-19 pneumonia a systematic review, meta-analysis, and meta-regression. Diabetes Metab Syndr. 2020;14(4):395-403. doi: https://doi.org/10.1016/j.dsx.2020.04.018

8. Hoffmann M, Kleine-Weber H, Schroeder S, et al. SARS-CoV-2 cell entry depends on ACE2 and TMPRSS2 and is blocked by a clinically proven protease inhibitor. Cell. 2020;181(2):271-280.e8. doi: https://doi.org/10.1016/j.cell.2020.02.052.

9. $\mathrm{Xu} \mathrm{H}$, Zhong L, Deng J, et al. High expression of ACE2 receptor of 2019-nCoV on the epithelial cells of oral mucosa. Int J Oral Sci. 2020;12(1):8. doi: https://doi.org/10.1038/s41368-020-0074-x

10. Zou X, Chen K, Zou J, et al. The single-cell RNA-seq data analysis on the receptor ACE2 expression reveals the potential risk of different human organs vulnerable to Wuhan 2019-nCoV infection. Front Med. 2020. doi: https://doi.org/10.1007/s1 1684-020-0754-0

11. Rabi FA, Al Zoubi MS, Kasasbeh GA, et al. SARS-CoV-2 and coronavirus disease 2019: what we know so far. Pathogens. 2020;9(3):231-235. doi: https://doi.org/10.3390/pathogens9030231

12. Roca-Ho H, Riera M, Palau V, et al. Characterization of ACE and ACE2 287 expression within different organs of the NOD mouse. Int J Mol Sci. 2017;18(3). pii: E563. doi: https://doi.org/10.3390/ijms18030563 
13. Brufsky A. Hyperglycemia, hydroxychloroquine, and the COVID-19 epidemic. J Medical Virology. 2020. doi: https://doi.org/10.1002/jmv.25887

14. Lin L, Lu L, Cao W, Li T. Hypothesis for potential pathogenesis of SARS-CoV-2 infection - a review of immune changes in patients with viral pneumonia. Emerg Microbes Infect. 2020;9(1):727-732. doi: https://doi.org/10.1080/22221751.2020.1746199

15. Wang Q, Fang P, He R, et al. O-GlcNAc transferase promotes influenza A virus-induced cytokine storm by targeting interferon regulatory factor-5. Sci Adv. 2020;6(16):eaaz7086. doi: https://doi.org/10.1126/sciadv.aaz7086

16. Guo W, Li M, Dong Y, et al. Diabetes is a risk factor for the progression and prognosis of COVID-19. Diabetes Metab Res Rev. 2020;e3319. doi: https://doi.org/10.1002/dmrr.3319

17. Yang JK, Feng Y, Yuan MY, et al. Plasma glucose levels and diabetes are independent predictors for mortality and morbidity in patients with SARS. Diabet Med. 2006;23(6):623-628 doi: https://doi.org/10.1111/j.1464-5491.2006.01861.x

18. Bode B, Garrett V, Messler J, et al. Glycemic characteristics and clinical outcomes of COVID-19 patients hospitalized in the United States. J Diabetes Sci Technol. 2020;1932296820924469. doi: https://doi.org/10.1177/1932296820924469

19. Wang B, Li R, Lu Z, Huang Y. Does comorbidity increase the risk of patients with COVID-19: evidence from metaanalysis. Aging (Albany NY). 2020;12(7):6049-6057. doi: https://doi.org/10.18632/aging.103000

20. Daousi C, Casson IF, Gill GV, et al. Prevalence of obesity in type 2 diabetes in secondary care: association with cardiovascular risk factors. Postgrad Med J. 2006;82(966):280-284. doi: https://doi.org/10.1136/pmj.2005.039032

21. Garg S, Kim L, Whitaker M, et al. Hospitalization rates and characteristics of patients hospitalized with laboratory-confirmed coronavirus disease 2019 - COVID-NET, 14 states, march 1-30, 2020. MMWR Morb Mortal WklyRep. 2020;69(15):458-464. doi: https://doi.org/http://dx.doi.org/10.15585/mmwr.mm6915e3

22. Hales CM, Carroll MD, Fryar CD, Ogden CL. Prevalence of obesity and severe obesity among adults: United States, 2017-2018. NCHS Data Brief No. 360, February 2020. Avalable from: https://www.cdc.gov/nchs/data/databriefs/db360-h.pdf

23. Simmonet $\mathrm{A}$, Chetboun $\mathrm{M}$, Poissy J, et al. High prevalence of obesity in severe acute respiratory syndrome coronavirus-2 (SARS-CoV-2) requiring invasive mechanical ventilation. Obesity (Silver Spring) 2020. Avalable from: https://onlinelibrary.wiley.com/doi/epdf/10.1002/oby.22831

24. Временные методические рекомендации: профилактика, диагностика и лечение новой коронавирусной инфекции (COVID-19), 6-я версия от 28.04.20 (static-1.rosminzdrav.ru). Минздрав России, 2020. [Vremennyye metodicheskiye rekomendatsii: profilaktika, diagnostika i lecheniye novoy koronavirusnoy infektsii (COVID-19), 6-ya versiya ot 28.04.20 (static-1.rosminzdrav.ru). Minzdrav Rossii; 2020. (In Russ.)] Доступно по: https://static-1.rosminzdrav.ru/system/attachments/ attaches/000/050/122/original/28042020_\%D0\%9CR_COVID-19_ v6.pdf. Ссылка активна на 28.04.2020.

25. Bornstein SR, Rubino F, Khunti K, et al. Practical recommendations for the management of diabetes in patients with COVID-19. Lancet Diabetes Endocrinol. 2020. pii: S2213-8587(20)30152-2. doi: https://doi.org/10.1016/S2213-8587(20)30152-2

26. Egi M. Acute glycemic control in diabetics. How sweet is optimal? Con: Just as sweet as in nondiabetic is better. J Intensive Care. 2018;6:70. doi: https://doi.org/10.1186/s40560-018-0337-1

27. Mendy A, Gopal R, Alcorn JF, Forno E. Reduced mortality from lower respiratory tract disease in adult diabetic patients treated with metformin. Respirology. 2019;24(7):646-651. doi: https://doi.org/10.1111/resp.13486

28. Ho T, Huang C, Tsai Y, et al. Metformin use mitigates the adverse prognostic effect of diabetes mellitus in chronic obstructive pulmonary disease. Respir Res. 2019;20(1):69. doi: https://doi.org/10.1186/s12931-019-1035-9

29. Мокрышева Н.Г., Галстян Г.Р., Киржаков М.А., и др. Рекомендации для врачей по лечению эндокринных заболеваний в условиях пандемии COVID-19. Пандемия COVID-19 и эндокринопатии. М.: ФГБУ «НМИЦ эндокринологии», 2020. [Mokrysheva NG, Galstyan GR, Kirzhakov MA, et al. Rekomendatsii dlya vrachey po lecheniyu endokrinnykh zabolevaniy v usloviyakh pandemii COVID-19.
Pandemiya COVID-19 i endokrinopatii. Moscow: FGBU «NMITS endokrinologii»; 2020. (In Russ.)] Доступно по: https://www. endocrincentr.ru/rekomendacii-dlya-vrachey-po-lecheniyuendokrinnyh-zabolevaniy-v-usloviyah. Ссылка активна на 28.04.2020.

30. Гринева Е.Н., Халимов Ю.Ш., Бабенко А.Ю., и др. Рекомендации по ведению больных COVID-19 и эндокринными заболеваниями в период пандемии. - М.: ФГБУ «НМИЦ им. В.А. Алмазова», 2020. [Grineva EN, KHalimov YuSh, Babenko AYu, et al. Rekomendatsii po vedeniyu bol'nykh COVID-19 i endokrinnymi zabolevaniyami v period pandemii. Moscow: FGBU «NMITS im. V.A. Almazova»; 2020 (In Russ.)] Доступно по: http://www.almazovcentre.ru/?p=62944. Ссылка активна на 28.04.2020.

31. Royal Australian College of General Practitioners (RACGP). Diabetes management during the coronavirus pandemic: be proactive and prepared. Avalable from: https://www.racgp.org.au/ getmedia/97a5abb4-1290-42cb-91c0-eabcaa8ca590/Diabetesmanagement-during-coronavirus-pandemic_1.pdf.aspx

32. Hartmann-Boyce J, Morris E, Goyder C, et al. Managing diabetes during the COVID-19 pandemic. [cited 8 April 2020] Avalable from: https://www.cebm.net/covid-19/managing-diabetes-during-thecovid-19-pandemic/

33. Christiansen C, Johansen M, Christensen S, et al. Preadmission metformin use and mortality among intensive care patients with diabetes: a cohort study. Crit Care. 2013;17(5):R192. doi: https://doi.org/10.1186/cc12886

34. Dapagliflozin in Respiratory Failure in Patients With COVID-19 (DARE-19). [cited 17 April 2020] Avalable from: https://clinicaltrials.gov/ct2/show/NCT04350593

35. Wiviott SD, Raz I, Bonaca MP, et al Dapagliflozin and Cardiovascular Outcomes in Type 2 Diabetes. N Engl J Med. 2019;380(4):347-357. doi: https://doi.org/10.1056/NEJMoa1812389

36. McMurray JJ, Solomon SD, Inzucchi SE, et al. DAPA-HF trial committees and investigators. dapagliflozin in patients with heart failure and reduced ejection fraction. N Engl J Med. 2019;381(21):1995-2008. doi: https://doi.org/10.1056/NEJMoa1911303

37. Дедов И.И., Шестакова М.В., Майоров А.Ю., и др. Алгоритмы специализированной медицинской помощи больным сахарным диабетом / Под ред. И.И. Дедова, М.В. Шестаковой, А.Ю. Майорова. 9-й вып. // Сахарный дuaбem. - 2019. - T. 22. - №s1-1. - C. 1-144. [Dedov II, Shestakova MV, Mayorov AYu, et al. Standards of specialized diabetes care. Ed. by Dedov II, Shestakova MV, Mayorov AYu. 9th edition. Diabetes mellitus. 2019;22(S1-1):1-144. (In Russ.)] doi: https://doi.org/10.14341/DM221S1

38. Petrillo MG, Bortner C, Cidlowski JA. Glucocorticoids: inflammation and immunity. The HypothalamicPituitary-Adrenal Axis in Health and Disease.2017;43-63. doi: https://doi.org/10.1007/978-3-319-45950-9_3

39. Russell B, Moss C, Rigg A, Hemelrijck MV. COVID-19 and treatment with NSAIDs and corticosteroids: should we be limiting their use in the clinical setting? Ecancer. 2020;14:1023. doi: https://doi.org/10.3332/ecancer.2020.1023

40. Zhao Z, Zhang F, Xu M, et al. Description and clinical treatment of an early outbreak of severe acute respiratory syndrome (SARS) in Guangzhou, PR China. J Med Microbiol. 2003;52(Pt 8):715-720. https://doi.org/10.1099/jmm.0.05320-0

41. Peng YD, Meng K, Guan HQ, et al. [Clinical characteristics and outcomes of 112 cardiovascular disease patients infected by 2019-nCoV. (In Chinese)]. Zhonghua Xin Xue Guan Bing Za Zhi. 2020;48:E004. https://doi.org/10.3760/cma.j.cn112148-20200220-00105

42. European Society of Cardiology. Position statement of the ESC Council on Hypertension on ACE-inhibitors and angiotensin receptor blockers. [cited 13 March 2020] Avalable from: https://www.escardio. org/Councils/Council-on-Hypertension-(CHT)/News/positionstatement-of-the-esc-council-on-hypertension-on-ace-inhibitorsand-ang

43. American Heart Association. HFSA/ACC/AHA statement addresses concerns re: using RAAS antagonists in COVID-19. [cited 20 March 2020] Avalable from: https://professional.heart.org/professional/ ScienceNews/UCM 505836 HFSAACCAHA-statement-addressesconcerns-re-using-RAAS-antagonists-in-COVID-19.jsp 


\section{ИНФОРМАЦИЯ ОБ АВТОРАХ [AUTHORS INFO]}

*Шестакова Марина Владимировна, д.м.н., профессор, академик PAH [Marina V. Shestakova, MD, PhD, Professor]; адрес: Россия, 117036 Москва, ул. Дм. Ульянова, д. 11 [address: 11 Dm. Ulyanova street, 117036 Moscow, Russian Federation]; ORCID: https://orcid.org/0000-0002-5057-127X; eLibrary SPIN: 7584-7015; e-mail: nephro@endocrincentr.ru

Мокрышева Наталья Георгиевна, д.м.н., профессор, член-корр. РAH [Natalia G. Mokrysheva, MD, PhD, Professor]; ORCID: https://orcid.org/0000-0002-9717-9742; eLibrary SPIN: 5624-3875; e-mail: nm70@mail.ru

Дедов Иван Иванович, д.м.н., профессор, академик PAH [Ivan I. Dedov, MD, PhD, Professor];

ORCID: https://orcid.org/0000-0002-8175-7886; eLibrary SPIN: 5873-2280; e-mail: dedov@endocrincentr.ru

\section{ЦИТИРОВАТЬ:}

Шестакова М.В., Мокрышева Н.Г., Дедов И.И. Сахарный диабет в условиях вирусной пандемии COVID-19: особенности течения и лечения// Сахарный диабет. - 2020. — Т. 23. — №2. — С. 132-139. doi: https://doi.org/10.14341/DM12418

\section{TO CITE THIS ARTICLE:}

Shestakova MV, Mokrysheva NG, Dedov II. Course and treatment of diabetes mellitus in the context of COVID-19. Diabetes Mellitus. 2020;23(2):132-139. doi: https://doi.org/10.14341/DM12418 